\title{
ORIGINAL
}

\section{SITUACIÓN DE LOS DESINFECTANTES DE USO AMBIENTAL Y EN INDUSTRIA ALIMENTARIA REGISTRADOS EN ESPAÑA TRAS LA PUBLICACIÓN DE LA DIRECTIVA 98/8/CE}

\author{
Ana Jiménez Zabala (1), Mónica Otazua Font (1), Pepa Maiztegi Gallastegi (1), Elena \\ Serrano Ibarbia (1), Ana Juaristi Arrieta (2) y Loreto Santa Marina Rodríguez (1).
}

(1) Subdirección de Salud Pública de Gipuzkoa. Departamento de Sanidad y Consumo. Gobierno Vasco.

(2) Departamento de Medio ambiente. Ayuntamiento de Donostia-San Sebastián

\begin{abstract}
RESUMEN
Fundamentos: La Directiva 98/8/CE armoniza y regula en el mercado europeo la autorización y registro de biocidas y establece un periodo de 14 años para la revisión de sustancias activas. Este trabajo analiza los cambios más relevantes producidos en el registro de biocidas desinfectantes registrados desde la publicación de la Directiva.

Métodos: La información se ha obtenido del registro de Biocidas publicado en la web del Ministerio de Sanidad, Política Social e Igualdad a mayo de 2010. Se ha utilizado una hoja de cálculo Excel para el volcado y tratamiento de los datos.

Resultados: Existen 1.575 biocidas desinfectantes (1137 formulados y 438 ingredientes activos técnicos) registrados en España destinados a uso ambiental y en industria alimentaria. Los formulados están compuestos por 56 sustancias activas que están siendo estudiadas para su inclusión en la lista comunitaria de sustancias autorizadas. El 54\% de los formulados están registrados como bactericida-fungicida, el $79 \%$ se aplican por contacto, el $42 \%$ son compuestos de amonio cuaternario y el $67.9 \%$ están elaborados con una sola sustancia activa. Respecto a su peligrosidad el $45.3 \%$ son corrosivos, el $25.7 \%$ irritantes, el $9.8 \%$ nocivos, el $1.1 \%$ tóxicos y el $33.1 \%$ son peligrosos para el medio ambiente.

Conclusiones: El registro de biocidas español se adecua a lo establecido en la Directiva cancelando los registros que contienen sustancias no incluidas en la lista. El 58\% de las sustancias activas de uso ambiental y el $76,4 \%$ de uso en industria alimentaria en revisión en Europa se encuentran autorizadas en España.
\end{abstract}

Palabras clave: Biocidas. Salud Pública. Desinfectante.

Correspondencia

Ana Jiménez Zabala

Subdirección de Salud Pública de Gipuzkoa

Avenida de Navarra 42013 Donostia

San Sebastián (Gipuzkoa)

mambien1-san@ej-gv.es

\section{ABSTRACT}

\section{Situation of Environmental and Food Area Disinfectants Registered in Spain Under Directive 98/8/CE}

Background: Directive 98/8/EC harmonizes and regulates in the European market authorization and registration of biocides and establishes a period of 14 years for review of active substances. This study analyzes the most significant changes produced in the registry of biocides used as disinfectants registered since the publication of the Directive.

Method: Information was obtained from the registry of biocides published in the website of the Ministry of Health, Social Policy and Equality in May 2010. We used an Excel data base for the dump and data processing.

Results: There are 1575 biocides with intended use as environmental and food area disinfectants registered in Spain (1137 formulas and 438 active ingredients). Formulas are composed of 56 active sustances which are being assessed for their inclusion in the Community list of authorized substances. $54 \%$ of the formulas are registered as both bactericide and fungicide, $79 \%$ are contact disinfectants, $42 \%$ of the formulas correspond to those composed of quaternary ammonium compounds and $67.9 \%$ are made with a single active substance. Regarding hazardous properties $45.3 \%$ are corrosive, $25.7 \%$ irritant, $9.8 \%$ harmful, $1.1 \%$ toxic , and $33.1 \%$ are dangerous to the environment.

Conclusions: The Spanish registry of biocides has complied with the provisions of the Directive cancelling the registrations of the formulas containing substances not included in the list. Of all the substances which are under review in Europe, $58 \%$ of environmental disinfectants and $76.4 \%$ of food area disinfectants are authorized in Spain.

Key words: Biocides. Public health. Disinfectant. 


\section{INTRODUCCIÓN}

Los biocidas son sustancias y preparados destinados a combatir la acción de los organismos nocivos por medios químicos y biológicos. La Directiva 98/8/CE, en adelante "Directiva", tiene por objeto armonizar y regular en el mercado europeo los procedimientos de autorización y registro de biocidas, además de procurar un alto nivel de protección para las personas, animales y medio ambiente ${ }^{1}$. Entre sus preceptos establece la creación de una lista comunitaria de sustancias activas autorizadas para la fabricación de biocidas, el procedimiento para la evaluación e inclusión de las sustancias en la lista y un sistema de intercambio de información técnica y administrativa entre las autoridades competentes.

La Directiva establecía un programa de trabajo de diez años, denominado "programa de revisión", para estudiar todas las sustancias activas que forman parte de los biocidas comercializados. El programa de revisión consiste básicamente en la identificación y notificación de la sustancia activa, evaluación de riesgo e inclusión en la lista positiva ${ }^{2,3}$. En mayo de 2010, fecha en la que concluía el plazo establecido para la finalización del programa, aún no se había completado la revisión de un importante número de sustancias activas. Previendo esta situación, en septiembre de 2009 se modificó la Directiva y se amplió el programa de revisión hasta mayo de $2014^{4}$.

La Directiva y su posterior modificación establecen, a su vez, una disposición transitoria por la que se permite a los Estados miembros aplicar durante estos 14 años sus normas o prácticas nacionales respecto a la comercialización de biocidas y, en particular, autorizar la comercialización de biocidas que contengan sustancias activas no incluidas todavía en la lista positiva que figura en los anexos I, IA o IB de dicha Directiva. Una vez finalizado el programa de revisión solo se permitirá la comercialización de biocidas cuyas sustancias activas estén incluidas en la lista comuni- taria de sustancias autorizadas. No obstante, durante el periodo transitorio, conforme se vayan tomando las decisiones de incluir o no las sustancias en los anexos, los Estados miembros deberán aplicar dichas disposiciones.

En España el RD 3349/1983 y sus modificaciones $^{5,6,7}$ constituyen el marco normativo básico por el que se regulan los plaguicidas hasta la aplicación total de la Directiva. En el mismo, los plaguicidas no agrícolas (denominados biocidas en la Directiva) se clasifican según sus usos (ganadero, higiene personal, e industria alimentaria y ambiental), adscribiéndose a las Direcciones correspondientes (Dirección de Ganadería del Ministerio de Medio Ambiente y Medio Rural y Marino, Dirección de Farmacia y Productos Sanitarios, y Dirección de Salud Pública del Ministerio de Sanidad, Política Social e Igualdad).

El RD 1054/2002 transpone la Directiva al ordenamiento jurídico español ${ }^{8}$. En él se definen cuatro grupos de biocidas, donde se incluyen 23 tipos de productos diferentes. Los biocidas definidos en el RD 3349/1983 como desinfectantes de uso ambiental y en la industria alimentaria, se incluyen en el grupo 1 (desinfectantes y biocidas generales) y se enmarcan dentro de los de tipo 2 (desinfectantes utilizados en los ámbitos de la vida privada y de la salud pública y otros biocidas) y tipo 4 (desinfectantes para las superficies que están en contacto con alimentos y piensos) respectivamente.

En la disposición adicional única del RD 1054/2002 se disponía que durante el periodo transitorio los biocidas (plaguicidas no fitosanitarios) siguieran adscritos a las Direcciones definidas en el RD 3349/1983. Además, se establecía un plazo de 6 meses para que los fitosanitarios utilizados como protectores para conservación de maderas, registrados en el Ministerio de Medio Ambiente y Medio Rural y Marino, se incluyeran en el registro de biocidas. Una vez finalizado el plazo todos los biocidas contemplados en la Directiva, eva- 
luados conforme al procedimiento establecido, se inscribirán en el Registro Oficial de Biocidas de la Dirección General de Salud Pública del Ministerio de Sanidad, Política Social e Igualdad.

Este trabajo tiene por objeto estudiar la situación actual de los desinfectantes de uso ambiental y en la industria alimentaria (tipo 2 y 4 según Directiva) inscritos en el registro de plaguicidas no agrícolas o biocidas de la Dirección General de Salud Pública, analizar los cambios más relevantes producidos en el mismo desde la publicación de la Directiva y evaluar el efecto de dichos cambios en el registro, con el fin de completar los estudios de revisión realizados por otros autores ${ }^{9-12}$ en el ámbito de los biocidas registrados en España.

\section{MATERIAL Y MÉTODO}

Se ha realizado el análisis de los biocidas registrados -ingredientes activos técnicos (IAT) y formulados-, y de las sustancias activas que los componen. La información objeto de análisis (composición, clasificación según su peligrosidad, finalidad, usos y aplicación) se ha obtenido de la base de datos del registro. Se ha utilizado una hoja de cálculo Excel para el volcado y tratamiento de los datos y para la elaboración de tablas y gráficos.

La selección de los biocidas de interés se realizó atendiendo a la información contenida en los apartados "Finalidad" y "Usos" del registro. Se volcaron unicamente los registros con finalidad bactericida y/o fungicida $\mathrm{y} / \mathrm{o}$ viricida que estaban inscritos para un uso ambiental y/o en industria alimentaria a 1 de mayo de $2010^{13}$.

La información relativa al estado en el que se encuentra, desde la publicación de la Directiva, el programa de revisión de biocidas a nivel europeo se ha obtenido de la página Web de la Dirección general de medio ambiente de la Comunidad Europea ${ }^{14-16}$.

\section{RESULTADOS}

En el registro de plaguicidas no arícolas o biocidas de la Dirección General de Salud Pública figuran 1575 biocidas desinfectantes registrados (bactericidas y/o fungicidas y/o viricidas) de los que 1137 (72\%) son formulados y 438 (28\%) IAT utilizados en la elaboración de los formulados. El 41\% (466) de los formulados son de uso ambiental y el 59\% (671) de uso en industria alimentaria. En cuanto a los IAT el $57,5 \%$ (252) son de uso ambiental, y el 42,5\% (186) de uso en industria alimentaria.

La información relativa a las 85 sustancias activas que forman parte de la composición de los 1575 biocidas registrados se recoge en las tablas 1 y 2 . Actualmente, dentro del programa de revisión, 56 sustancias están siendo estudiadas para su inclusión como biocidas de tipos 2 y/o 4 y las 29 restantes para su inclusión como otros tipos de biocidas contemplados entre los 23 tipos de la Directiva.

En la tabla 1 se muestra, para cada una de las 56 sustancias activas actualmente en revisión, el grupo químico en el que se ha clasificado a efectos de este estudio, su denominación, $n^{\circ} \mathrm{CAS}$, tipo/s de biocida para los que se encuentra en revisión, número de IAT y formulados de los que forma parte según el ámbito de uso, y la peligrosidad de los IAT en relación a sus efectos en salud y medio ambiente.

El 20\% de las sustancias activas son ácidos y sales, el 14\% amonios cuaternarios, el 11\% fenoles, el 9\% cloro y derivados, y el resto de sustancias pertenecen a otros grupos entre los que se encuentran alcoholes, aldehídos, peróxidos, etc. En lo relativo a los IAT registrados, la mayor parte de ellos son derivados de cloro $(21 \%)$, peróxidos $(20 \%)$ y compuestos de amonio cuaternario (19\%); siendo el hipoclorito sódico, el peróxido de hidrógeno y los compuestos de amonio cuaternario (BKC) los IAT que cuentan con mayor número de registros. 
Tabla 1

Listado de sustancias activas en revisión, que forman parte de la composición de IAT y formulados

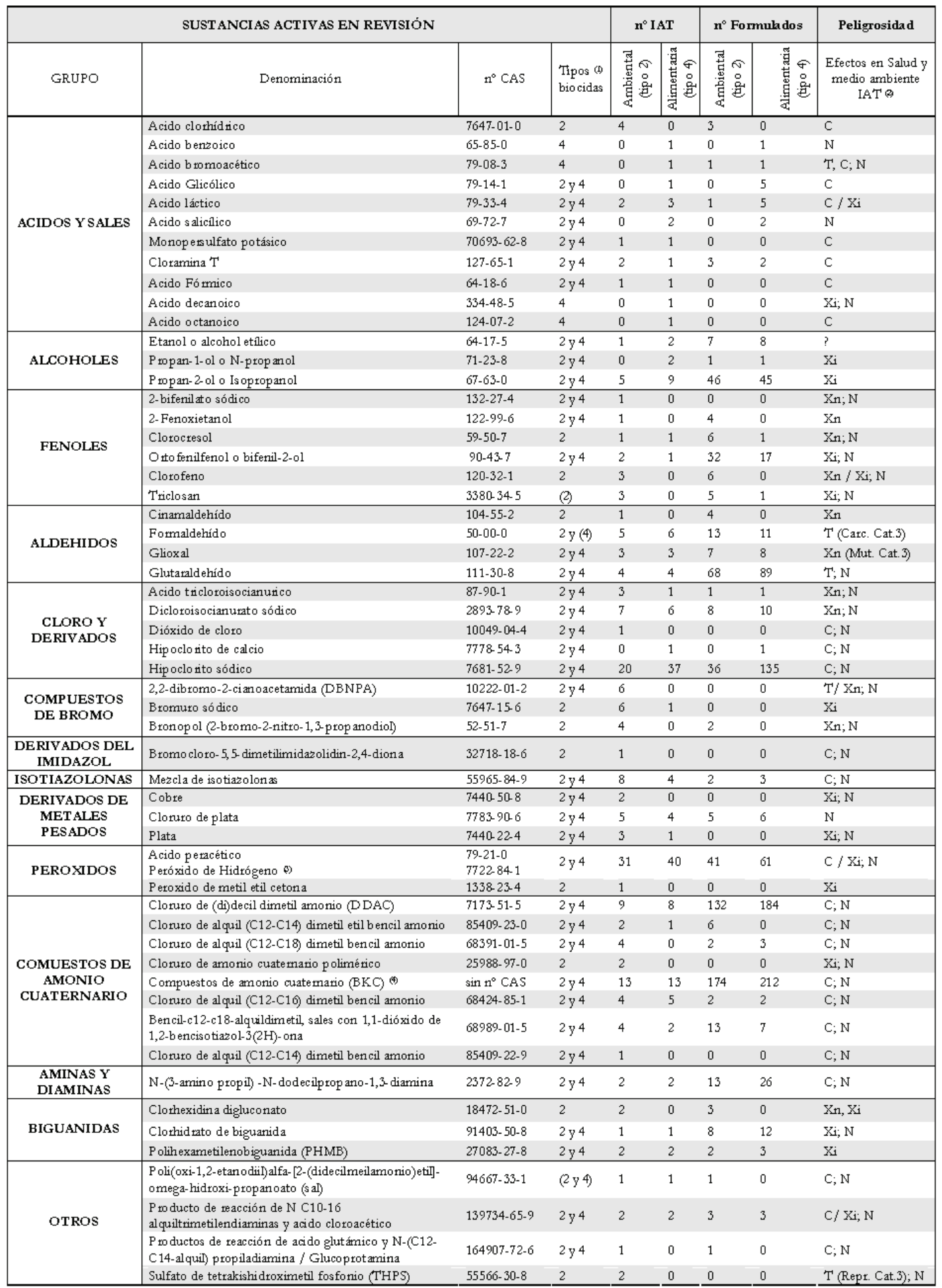


(1) Tipo/s de producto para los que se ha presentado un expediente para su evaluación según (EC)2032/2003. Los números entre paréntesis corresponden a los tipos de producto para los que se han notificado las sustancias pero que, de momento, no consta que se encuentren en revisión de acuerdo a la información publicada en la web de la Dirección General de Medio Ambiente de la CE

(2) T: Tóxico; Xn: Nocivo; C: Corrosivo; Xi: Irritante; N: Peligros para el medio ambiente; Carc: Cancerígeno; Mut: Mutágeno; Repr: Tóxico par la reproducción; Cat3: Categoría 3. (Se separan con una barra las distintas clasificaciones que aparecen debido a variaciones en los porcentajes de la sustancia en los IAT registrados)

(3) El 34\% de los registros están constituidos por la mezcla de ambas sustancias, el 55\% corresponde al peróxido de hidrógeno y el $11 \%$ al ácido peracético

(4) Cloruros, bromuros o hidróxidos de bencilalquildimetilo (alquilo de C8-22, saturado e insaturado, y alquilo de sebo, alquilo de coco y alquilo de soja). Sin $\mathrm{n}^{\circ}$ cas por tratarse de un grupo formado por varias sustancias, siendo la más habitual el Cloruro de Benzalconio

Como puede observarse en la tabla 1 , las sustancias activas no están igualmente representadas en los IAT y formulados. Por ejemplo, el glutaraldehído presente en 8 IAT registrados forma parte de la composición de 157 formulados biocidas desinfectantes. Las 8 sustancias activas clasificadas en el grupo de compuestos de amonio cuaternario forman parte de 68 IAT registrados, y están presentes en 737 formulados. Por otro lado, existen 15 sustancias activas que aún estando presentes en 34 IAT registrados no forman parte de la composición de ningún formulado.

La tabla 2 contiene las 29 sustancias activas para las que se ha tomado la decisión de no incluirlas en los anexos como biocidas de tipos 2 y 4 , que serán en adelante denominadas a efectos de este estudio "sustancias no incluidas". Para cada una de estas 29 sustancias activas se muestra el grupo químico en el que se ha clasificado, su denominación, $\mathrm{n}^{\mathrm{o}}$ CAS, motivo de no inclusión, número de IAT de los que forma parte la sustancia activa como ingrediente y su peligrosidad. El $34 \%$ de estas sustancias activas no fueron incluidas al no haberse notificado para su inclusión en los anexos como tipos 2 y 4 . El resto $(66 \%)$ no fueron incluidas al no haberse presentado la documentación necesaria para su evaluación. Como se puede observar, una importante cantidad de estas sustancias activas son fungicidas.

Un caso particular es el ácido ortofosfórico que habiendo sido notificado exclusivamente para su inclusión como producto de tipo 4 y posteriormente excluido del programa de revisión, fueron cancelados todos los IAT registrados en los que formaba parte y no figura en la tabla 2. Esta sustancia está presente en la composición de tres biocidas registrados pero con una finalidad no bactericida, para la que se han presentado los estudios de eficacia correspondientes.

En la tabla 3 se presenta el total de formulados registrados según grupo químico al que pertenecen las sustancias activas que forman parte del mismo y su ámbito de uso. El $67,9 \%$ de los formulados están compuestos por una sola sustancia activa y el resto por entre 2 y 5 sustancias activas pertenecientes a uno o más grupos químicos. El total de formulados elaborados con cloro y derivados están compuestos por una única sustancia activa y, la mayoría, incluyen el hidróxido sódico o potásico como aditivo estabilizador. Por el contrario, los formulados elaborados con alcoholes y compuestos de amonio cuaternario, frecuentemente incluyen además sustancias pertenecientes al resto de grupos químicos.

El porcentaje de formulados desinfectantes, según grupo químico al que pertenece la sustancia activa y uso se muestra en la figura 1. El grupo de amonios cuaternarios es el que presenta un mayor porcentaje de formulados, para ambos usos.

La finalidad de los IAT y formulados registrados según uso se recoge en la tabla 4. En el caso de los IAT, se diferencian los que incluyen sustancias activas que se encuen- 
Tabla 2

Listado de sustancias activas no incluidas como productos de tipos 2 y 4

\begin{tabular}{|c|c|c|c|c|c|c|}
\hline \multicolumn{4}{|c|}{ SUSTANCIAS ACTIVAS NO INCLUIDAS } & \multicolumn{2}{|c|}{ IAT } & \multirow{2}{*}{$\begin{array}{c}\text { Peligrosidad } \\
\text { Efectos en salud y } \\
\text { medio ambiente } \\
\text { IAT }^{(2)}\end{array}$} \\
\hline GRUPO & Denominación & $\mathrm{n}^{\circ} \mathrm{CAS}$ & 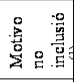 & $\begin{array}{l}\text { 焉令 } \\
\text { 量 } \\
\text { 虽 } \\
\end{array}$ & 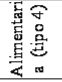 & \\
\hline \multirow[t]{4}{*}{ ACIDOS Y SALES } & Acido bórico & $10043-35-3$ & $\mathrm{E}$ & 1 & 0 & T (Repr Cat.2) \\
\hline & \begin{tabular}{|l|} 
Acido cítrico \\
\end{tabular} & $77-92-9$ & $\mathrm{E}$ & 2 & 1 & $\mathrm{C} / \mathrm{X}_{\mathbf{I}}$ \\
\hline & \begin{tabular}{|l|} 
Acido sórbico \\
\end{tabular} & $110-44-1$ & $\mathrm{E}$ & 1 & 1 & $\mathrm{Xi}$ \\
\hline & \begin{tabular}{|l|} 
Disodio tetraborato anhidro \\
\end{tabular} & $1330-43-4$ & $\mathrm{E}$ & 2 & 0 & T (Repr Cat.2) \\
\hline FENOLES & Diclorofeno & $97-23-4$ & $\mathrm{E}$ & 2 & 0 & $\mathrm{Xn} ; \mathbf{N}$ \\
\hline CLORO Y DERIVADOS & Clorito sódico & $7758-19-2$ & $\mathrm{E}$ & 2 & 1 & $\mathrm{~T} / \mathrm{Xn}$ \\
\hline COMPUESTOS DE YODO & Yodo & $7553-56-2$ & $\mathrm{E}$ & 1 & 3 & $\mathrm{Xn} ; \mathrm{N}$ \\
\hline COMPUESTOS DE BROMO & Clonuro de bromo & $13863-41-7$ & $\mathrm{E}$ & 1 & 0 & C \\
\hline \multirow{3}{*}{$\begin{array}{l}\text { DERIVADOS DEL } \\
\text { IMIDAZOL }\end{array}$} & 1,3-Dibromo-5,5-Dimetillidantoina & $77-48-5$ & $\mathrm{E}$ & 1 & 0 & $\mathbf{C}$ \\
\hline & 1,3-Dicloro-5,5-dimetilhidantoina & $118-52-5$ & $\mathrm{E}$ & 1 & 0 & $\mathrm{C} ; \mathrm{N}$ \\
\hline & \begin{tabular}{|l|} 
1,3-Dicloro-5-etil-5-metilhidantoina \\
\end{tabular} & 89415-87-2 & $\mathrm{E}$ & 1 & 0 & $\mathrm{~T} ; \mathbf{N}$ \\
\hline $\begin{array}{l}\text { FUNGICIDAS DE } \\
\text { IMIDAZOL }\end{array}$ & Imazalil & $35554-44-0$ & $\mathrm{E}$ & 3 & 3 & $\mathrm{Xn} ; \mathrm{N}$ \\
\hline \multirow{2}{*}{$\begin{array}{l}\text { FUNGICIDAS DE } \\
\text { CONAZOL }\end{array}$} & Propiconazol & $60207-90-1$ & $\mathrm{E}$ & 5 & 2 & $\mathrm{Xn} ; \mathrm{N}$ \\
\hline & \begin{tabular}{|l|} 
Tebuconazol \\
\end{tabular} & $107534-96-3$ & $\mathbf{N}$ & 4 & 1 & Xn (Repr Cat.3); N \\
\hline \multirow[t]{3}{*}{$\begin{array}{l}\text { FUNGICIDAS DE } \\
\text { COMPUESTOS DE COBRE }\end{array}$} & $\begin{array}{l}\text { Bis [1-ciclohexal-1,2 di(hidroxi)diazenioato(2)]- } \\
\text { cobre }\end{array}$ & $312600-89-8$ & $\mathrm{E}$ & 1 & 0 & $\mathrm{Xn} ; \mathrm{N}$ \\
\hline & \begin{tabular}{|l|} 
Carbonato de cobre \\
\end{tabular} & $12069-69-1$ & $\mathbf{N}$ & 4 & 0 & $\mathrm{Xn} ; \mathrm{N}$ \\
\hline & Oxido de cobre & $1317-38-0$ & $\mathbf{N}$ & 2 & 0 & $\mathrm{Xn} ; \mathrm{N}$ \\
\hline \multirow{2}{*}{ FUNGICIDAS DE AMIDAS } & Diclofluanida & $1085-98-9$ & $\mathbf{N}$ & 2 & 0 & $\mathrm{Xn} ; \mathrm{N}$ \\
\hline & Tolilfluanida & 731-27-1 & $\mathbf{N}$ & 2 & 0 & $\mathrm{~T} ; \mathbf{N}$ \\
\hline $\begin{array}{l}\text { FUNGICIDAS DE } \\
\text { CARBAMATO }\end{array}$ & IPBC (3-yodo-2-propiril butil carbamato) & $55406-53-6$ & $\mathbf{N}$ & 13 & 0 & $\mathrm{~T} ; \mathbf{N}$ \\
\hline ISOTIAZOLONAS & 2-octil-2 H-isotiazol-3-ona & $26530-20-1$ & $\mathrm{E}$ & 1 & 0 & $\mathrm{~T} ; \mathbf{N}$ \\
\hline $\begin{array}{l}\text { COMUESTOS DE AMONIO } \\
\text { CUATERNARIO }\end{array}$ & Compuestos de amonio cuaternario (TMAC) ${ }^{(3)}$ & $\operatorname{Sin} \mathrm{n}^{\circ} \mathrm{CAS}$ & $\mathbf{N}$ & 2 & 1 & $\mathbf{C} ; \mathbf{N}$ \\
\hline AMINAS Y DIAMINAS & $\begin{array}{l}\text { Copolimero de éter } \mathbf{N , N}, N^{\prime} \cdot N^{\prime} \text {-tetrametilendiamina- } \\
\text { bis-(2-cloroetilico) }\end{array}$ & $31075-24-8$ & $\mathrm{E}$ & 1 & 0 & $\mathrm{Xn} ; \mathrm{N}$ \\
\hline METALES PESADOS & Oxido de plata & $20667-12-3$ & $\mathbf{N}$ & 1 & 0 & $\mathrm{Xi} ; \mathrm{N}$ \\
\hline \multirow[t]{5}{*}{ OTROS } & Ditiocianato de metilo & $6317-18-6$ & $\mathbf{N}$ & 1 & 0 & $\mathrm{~T}+; \mathbf{N}$ \\
\hline & Creosota & 8001-58-9 & $\mathbf{N}$ & 2 & 0 & $\mathrm{~T}$ (Carc Catt2); $\mathrm{N}$ \\
\hline & \begin{tabular}{|l|} 
Clonuro de tributilo tetradecilo de fosfonio \\
\end{tabular} & 81741-28-8 & $\mathrm{E}$ & 1 & 0 & $\mathrm{C} ; \mathbf{N}$ \\
\hline & Dimetilditiocarbamato potásico & $128-03-0$ & $\mathrm{E}$ & 1 & 0 & $\mathrm{Xn} ; \mathrm{N}$ \\
\hline & \begin{tabular}{|l|} 
Terbutilazina \\
\end{tabular} & $5915-41-3$ & $\mathrm{E}$ & 1 & 0 & $\mathrm{Xn} ; \mathrm{N}$ \\
\hline
\end{tabular}

(1) N: Notificación no realizada para los tipos 2 y 4; E: Expediente no presentado para la evaluación como producto de tipo 2 y 4. (2) T: Tóxico; T+: Muy Tóxico; Xn: Nocivo; C: Corrosivo; Xi: Irritante; N: Peligroso para el medio ambiente; Carc: Cancerígeno; Mut: Mutágeno; Repr: Tóxico par la reproducción; Cat3: Categoría 3. (Se separan con una barra las distintas clasificaciones que aparecen debido a variaciones en los porcentajes de la sustancia en los IAT registrados). (3)Cloruros, bromuros o metil sulfatos de alquiltrimetilo (alquilo de C8-C18, saturado e insaturado, y alquilo de sebo, alquilo de coco y alquilo de soja). Sin número CAS por tratarse de una mezcla de varias sustancias

tran en revisión para su inclusión en los anexos como tipos 2 y/o 4 y los que contienen sustancias activas no incluidas. Se observa un escaso número de formulados fungicidas, tanto para uso ambiental $(0,9 \%)$ como para uso en industria alimentaria $(0,4 \%)$. Esto se debe a la cancelación de formulados elaborados a partir de IAT, con finalidad fungicida, que contenían sustancias activas para las que se ha tomado la decisión de no incluidas en los anexos.

La información relativa a los efectos en salud y el medio ambiente de los IAT elaborados con sustancias activas en revisión y no incluidas se resume en la figura 2. La mayor proporción de IAT muy tóxicos $(\mathrm{T}+)$, tóxi$\cos (\mathrm{T}), \mathrm{y}$ nocivos $(\mathrm{Xn})$ corresponde a los elaborados con sustancias activas no incluidas. Entre los que contienen sustancias activas en revisión, predominan los corrosivos (C) e irritantes (Xi). La proporción de IAT clasificados como carcinógenos, mutágenos y tóxicos para la reproducción (CMR) es mayor entre los elaborados con sustancias activas no incluidas. En cuanto al porcentaje de IAT clasificados como peligrosos para el medio ambiente $(\mathrm{N})$, es similar y elevado en ambos grupos.

La peligrosidad de los formulados resulta de la concentración y tipo de IAT utilizado en su fabricación. En la tabla 5 se resume dicha información según forma de aplicación y ámbito de uso. El 45,3\% de los formulados son corrosivos, el $25,7 \%$ irritantes, 
Tabla 3

Total de formulados registrados según grupo químico y ámbito de uso

\begin{tabular}{|c|c|c|}
\hline Grupo químico & Ambiental & $\begin{array}{c}\text { Industria } \\
\text { alimentaria }\end{array}$ \\
\hline ALDEHIDOS & 19 & 25 \\
\hline CLORO Y DERIVADOS & 45 & 147 \\
\hline PE ROXIDOS & 31 & 52 \\
\hline CACs & 205 & 271 \\
\hline CACs + ALCOHOLES & 24 & 26 \\
\hline CACs + ALDEHIDOS & 41 & 52 \\
\hline RESTO: & 101 & 98 \\
\hline Acidos y Sales & 4 & 7 \\
\hline Fenoles & 14 & 6 \\
\hline Alcoholes + Fenoles & 9 & 1 \\
\hline Alcoholes & 2 & 3 \\
\hline Biguanidas & 5 & 6 \\
\hline $\begin{array}{r}\text { Biguanidas }+ \text { Alcoholes }+ \text { Acidos y } \\
\text { Sales }\end{array}$ & 0 & 1 \\
\hline CACs + Biguanidas & 5 & 4 \\
\hline CACs + Biguanidas + Alcoholes & 1 & 1 \\
\hline CACs + Biguanidas + Isotiazolonas & 0 & 1 \\
\hline Aminas y Diaminas + Acidos y Sales & 0 & 1 \\
\hline CACs + Aminas y Diaminas & 7 & 9 \\
\hline Aminas y Diaminas + Biguanidas & 1 & 1 \\
\hline Aminas y Diaminas & 5 & 15 \\
\hline Otros & 2 & 2 \\
\hline Aldehidos + Alcohol & 1 & 4 \\
\hline Aldehidos + Alcohol + Fenoles & 3 & 3 \\
\hline Aldehidos + Fenoles & 1 & 1 \\
\hline Peróxidos + Metales pesados & 5 & 6 \\
\hline CACs + Acidos y Sales & 4 & 2 \\
\hline CACs + Fenoles & 7 & 4 \\
\hline CACs + Alcoholes + Fenoles & 4 & 2 \\
\hline CACs + Isotiazolonas & 2 & 1 \\
\hline CACs + Peróxidos & 3 & 1 \\
\hline Acidos + Alcoholes & 0 & 1 \\
\hline Peróxidos + Alcoholes & 1 & 1 \\
\hline Otros + Alcoholes & 1 & 1 \\
\hline CACs + Acidos y Sales + Alcoholes & 0 & 1 \\
\hline CACs + Aldehidos + Alcoholes & 5 & 8 \\
\hline CACs + Aldehidos + Fenoles & 5 & 1 \\
\hline Isotiazolonas & 0 & 1 \\
\hline Derivados de Bromo + Aldehidos & 2 & 0 \\
\hline Peroxidos + Otros & 1 & 0 \\
\hline Peroxidos + Acidos y Sales & 0 & 1 \\
\hline CACs + Aldehidos + Acidos y Sales & 0 & 1 \\
\hline CACs + Alcoholes + Otros & 1 & 0 \\
\hline TOTAL & 466 & 671 \\
\hline
\end{tabular}

el $9,8 \%$ nocivos y el $1,1 \%$ tóxicos. El $33,1 \%$ de los preparados se clasifican como peligrosos para el medio ambiente. El mayor número de formulados clasificados como corrosivos y peligrosos para el medio ambiente entre los de uso en industria alimentaria se debe a la mayor presencia de compuestos de cloro y derivados en su composición. En cuanto a la forma de aplicación, el 79,5\% de los formulados están registrados como desinfectantes de contacto de superficies y equipos, el 7,7\% para la desinfección aérea y el $12,8 \%$ restante se aplica de las dos formas.

La figura 3 resume la situación de las sustancias activas desinfectantes de tipo 2 y 4 (uso ambiental e industria alimentaria) a lo largo del programa de revisión en Europa. De las 964 sustancias activas identificadas como biocidas, 416 (43\%) fueron notificadas para su inclusión en los anexos, 165 como producto tipo 2 y 108 como tipo 4, el resto fueron excluidas del programa de revisión. El total de expedientes completos presentados para su evaluación en relación a estas sustancias ha sido 86 y 55 respectivamente.

En cuanto a las 56 sustancias activas en revisión, que forman parte de formulados desinfectantes inscritos en el registro de la Dirección de Salud Pública, 50 lo están para su inclusión como producto de tipo 2 y 42 como tipo 4 , lo que representa un $58 \%$ y $76,4 \%$, respectivamente, con respecto a las sustancias en revisión a nivel europeo. En el momento de esta revisión, al no haberse concluido su evaluación, ninguna de estas sustancias se ha incluido aún en los anexos de la Directiva.

\section{DISCUSION}

La publicación de la Directiva ha tenido un impacto notable en el mercado europeo de productos biocidas al haber sido retirados del mercado todos los formulados elaborados con sustancias excluidas del programa de revisión. 
Figura 1

Porcentaje de formulados según uso y grupo químico al que pertenece la sustancia activa

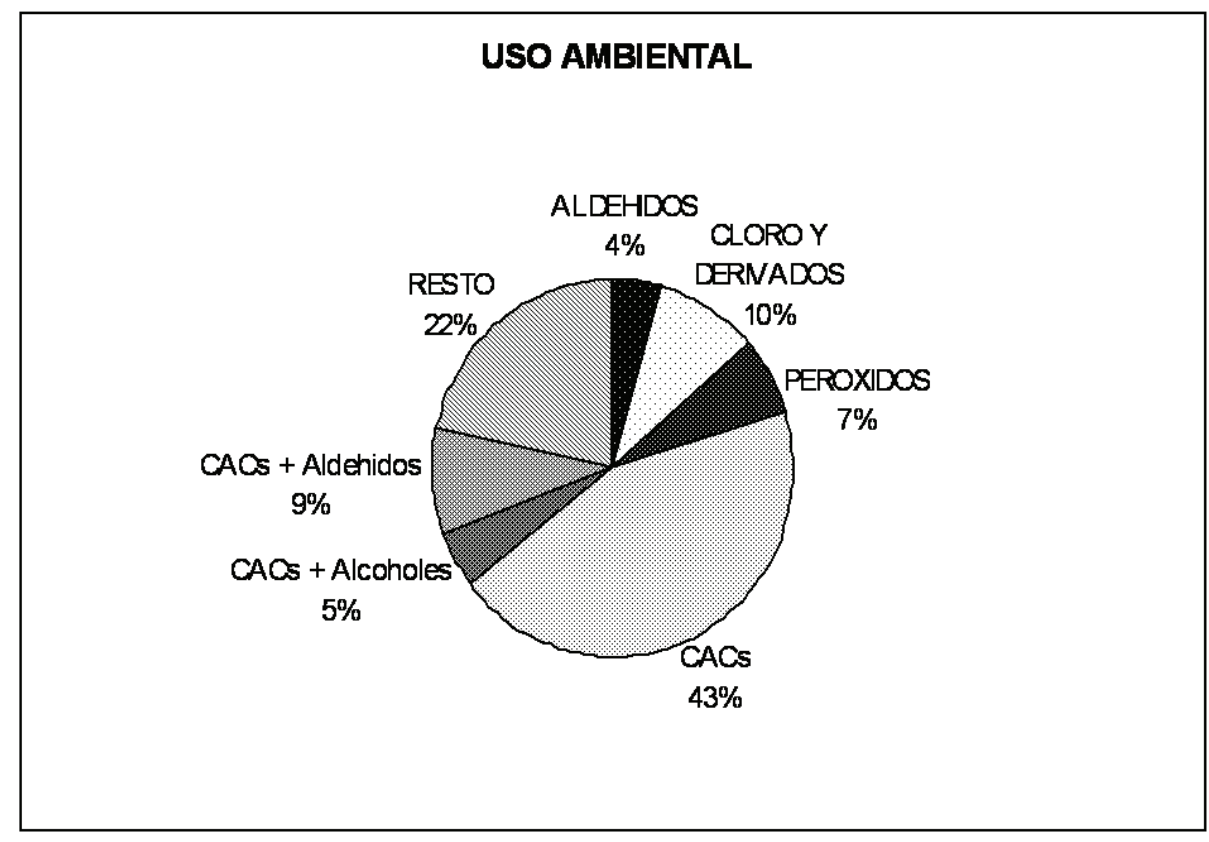

\section{USO INDUSTRIA ALIMENTARIA}

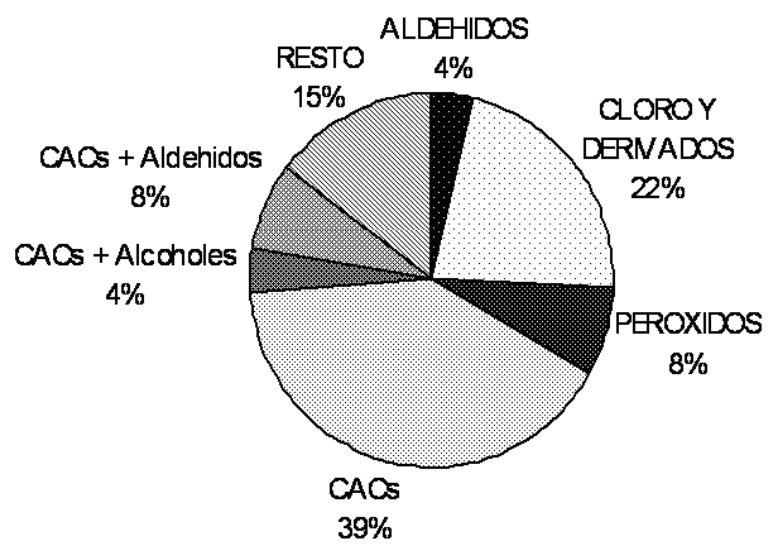

CACs: Compuestos de amonio cuaternario 


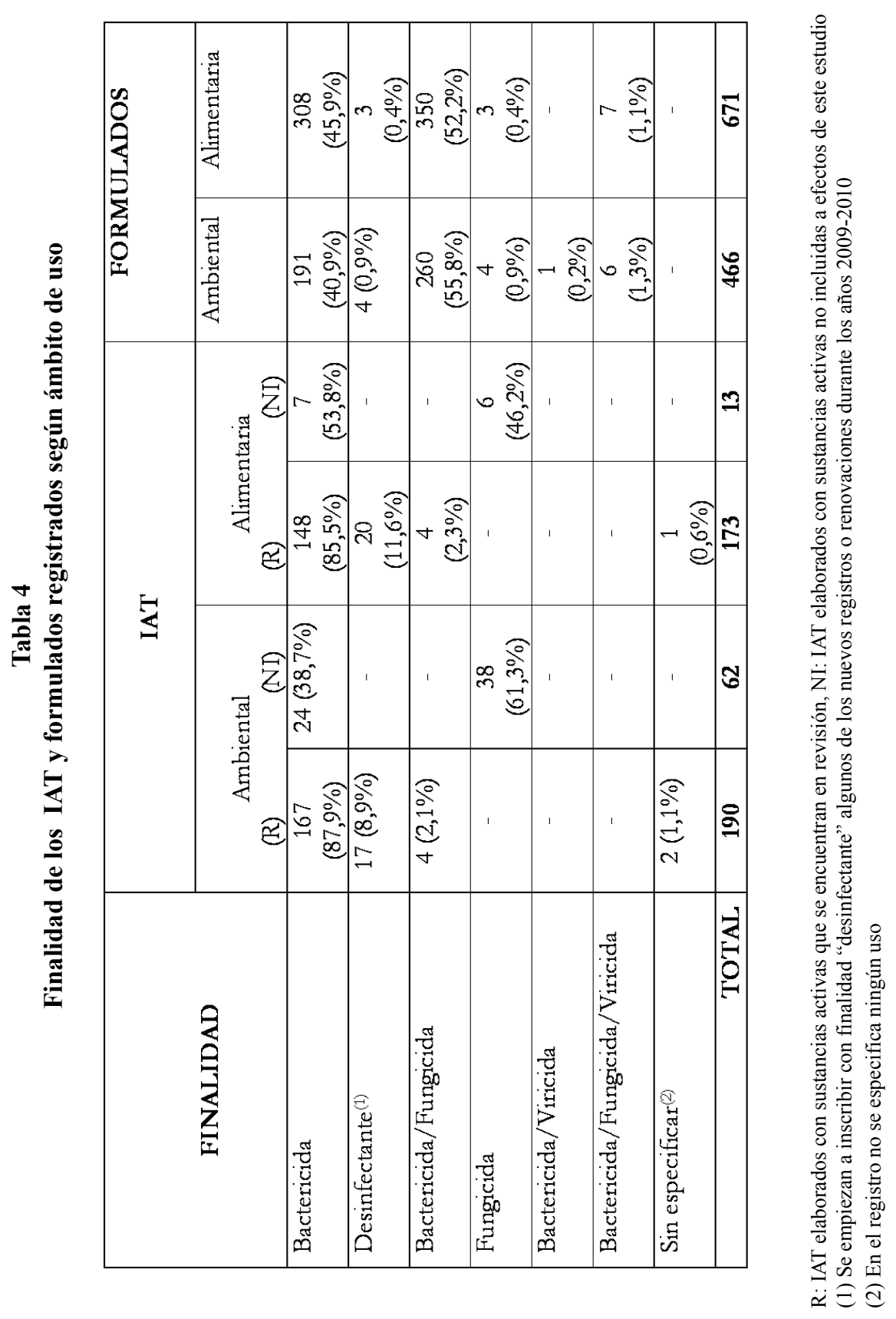


Figura 2

Peligrosidad de los IAT según sustancia activa

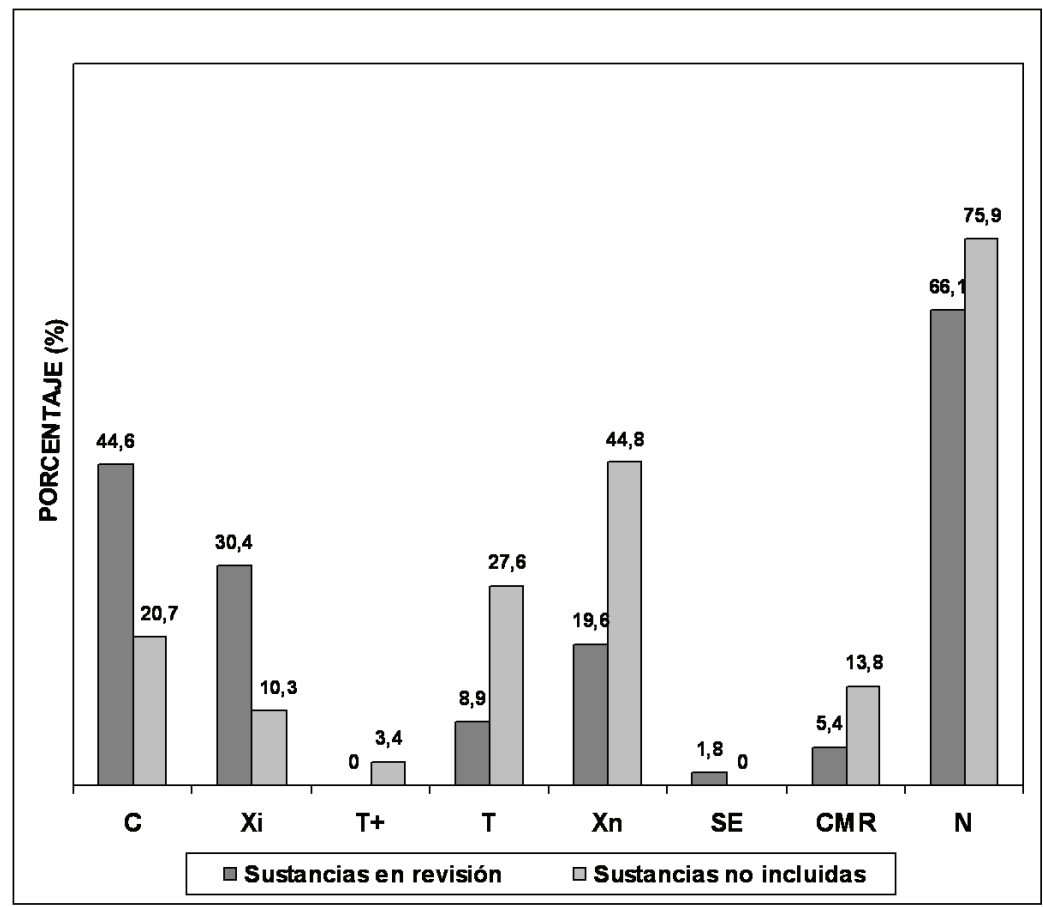

C: Corrosivo, Xi. Irritante, T+: Muy tóxico, T: Tóxico, Xn: Nocivo, SE: Sin efectos sobre salud y medio ambiente, CMR: Cancerígeno, mutágeno y tóxico para la reproducción, N: Peligroso para el medio ambiente

Inicialmente 548 sustancias activas fueron excluidas por no haber sido notificadas para ningún tipo de producto biocida. Se ha estimado que estas sustancias estaban presentes entre el $13 \%$ y el $33 \%$ de los formulados biocidas existentes en el mercado europeo, y se correspondían con las que ya no estaban en uso y con las que presentaban un perfil toxicológico que hacía difícil que pudieran superar con éxito la fase de evaluación ${ }^{17,18}$. Más tarde, fueron excluidas las sustancias activas que, a pesar de haber sido notificadas, no presentaron los expedientes de evaluación completos en el plazo establecido.

Los datos obtenidos en esta revisión refuerzan la idea de que la toxicidad fue, entre otros, uno de los motivos que influyeron a la hora de tomar la decisión de defen- der o no la inclusión de una sustancia activa en los anexos. Así, en este estudio se ha encontrado una mayor proporción de IAT muy tóxicos, tóxicos, nocivos y CMR entre los elaborados con sustancias activas que o bien no fueron notificadas o bien no se presentó finalmente la documentación necesaria para su evaluación.

Este trabajo confirma los progresivos cambios y adaptaciones que se han producido a lo largo de estos últimos 10 años en el registro de los desinfectantes de uso ambiental y en la industria alimentaria en España conforme a lo establecido en la normativa comunitaria de biocidas. De esta forma se han ido cancelado los formulados desinfectantes que contenían sustancias activas para las que se fueron tomando decisiones de no 


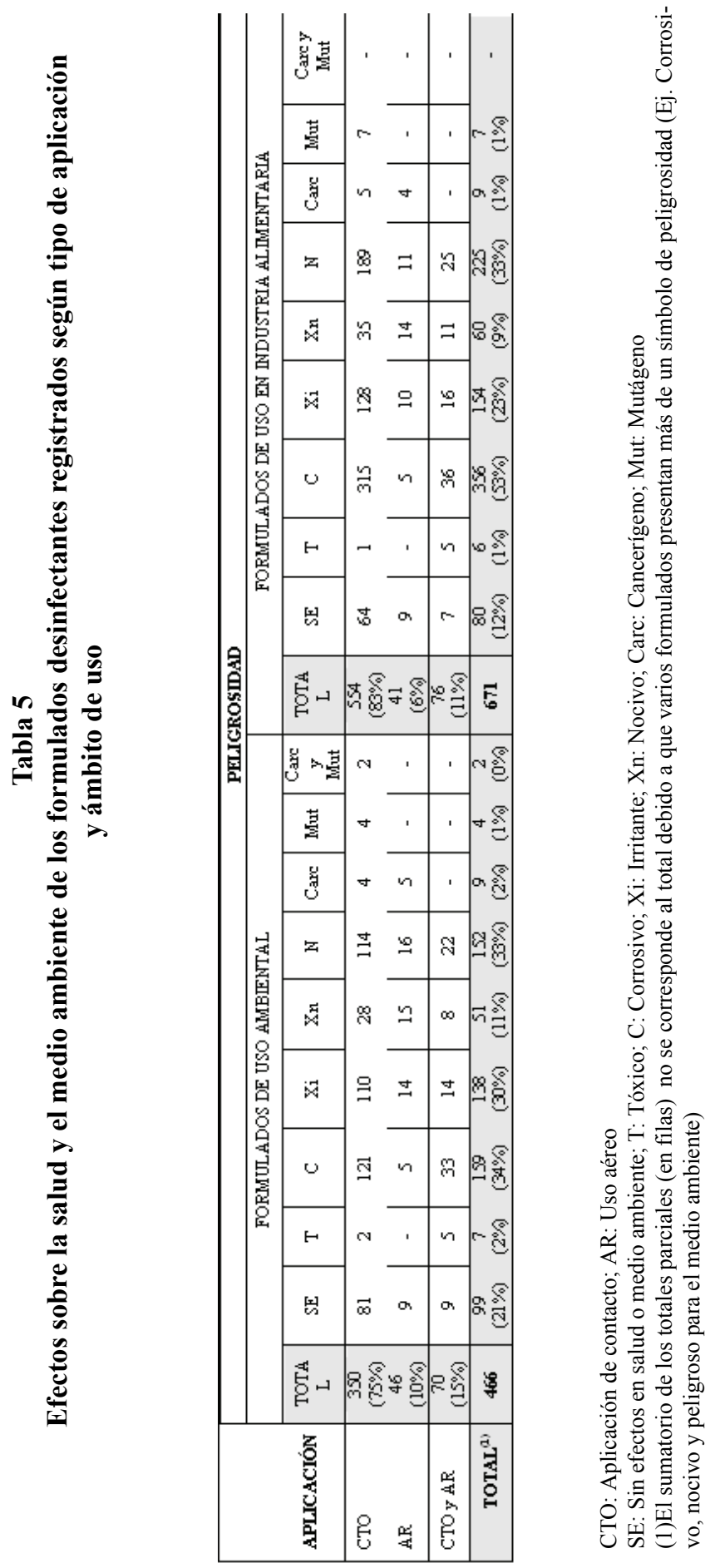


FIGURA 3

Situación de las sustancias activas a lo largo del programa de revisión en Europa

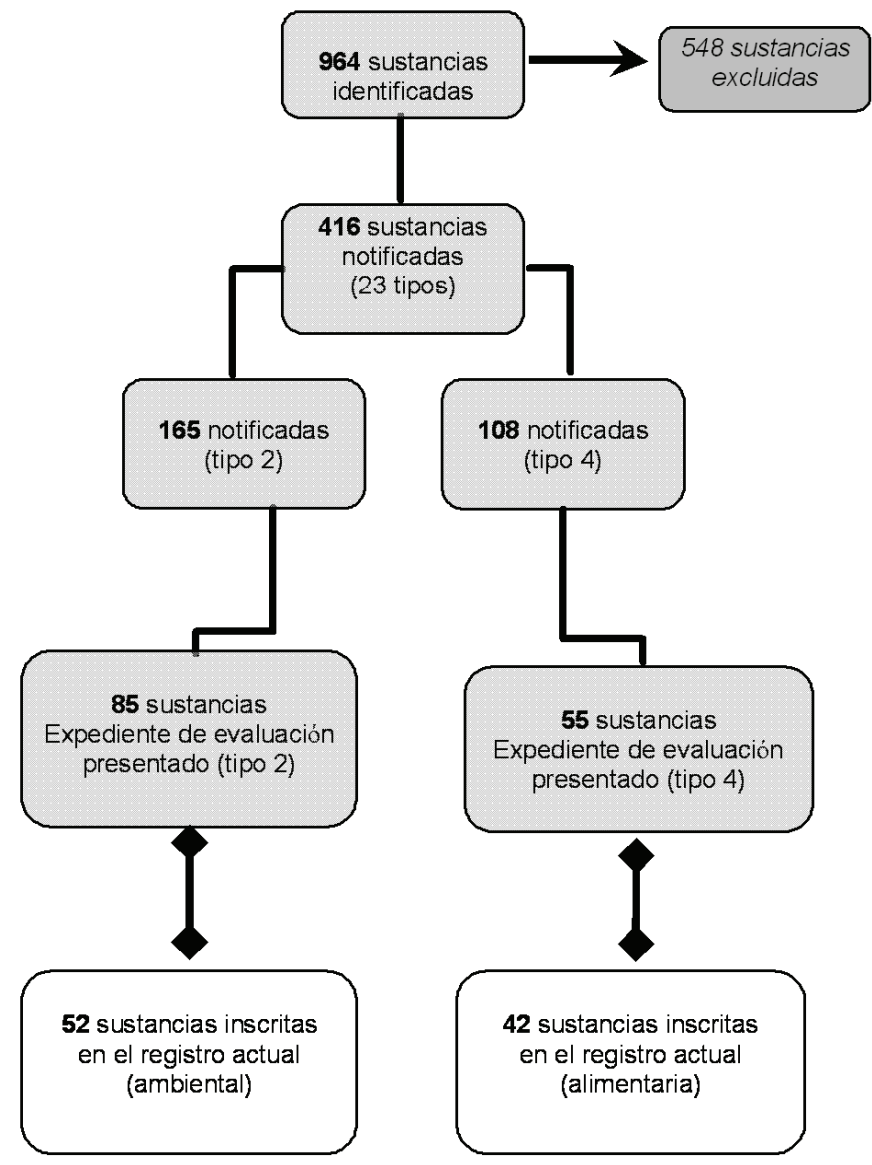

inclusión, con un par de salvedades. Así entre las sustancias activas no incluidas como tipo 2, el ácido bromacético se encuentra presente en un formulado registrado para uso ambiental y entre las no incluidas como tipo 4, el clorocresol forma parte de la composición de otro formulado para uso en industria alimentaria.

A partir de la información contenida en los informes presentados durante la fase de notificación se ha estimado el volumen de producción de sustancias activas en el espacio económico Europeo ${ }^{19}$. Entre las de tipo 2 las más representativas han sido el cloro, óxido de etileno, peróxido de hidrógeno, hipoclorito sódico, tricloroisocianurato sódico y dicloroisocianurato sódico, y entre las de tipo 4, el dióxido de cloro, peróxido de hidrógeno, hipoclorito sódico, ácido láctico y ácido peracético, que suponen el $90 \%$ y $94 \%$, de la producción del total de sustancias notificadas para tipo 2 y tipo 4 .

Si comparamos estos datos con los obtenidos en este estudio, podemos comprobar que el cloro y el óxido de etileno, dos de las seis sustancias activas de tipo 2 más representati- 
vas en cuanto a volumen de producción en Europa, no forman parte de ningún formulado desinfectante inscrito en el registro para uso ambiental. Hay que señalar, sin embargo, que la definición de plaguicida de uso ambiental recogida en el RD 3349/1983 no contemplaba ciertos biocidas que la Directiva clasifica como productos de tipo 2 , como es el caso de los desinfectantes de uso en piscinas y los desinfectantes utilizados para la limpieza y desinfección de centros sanitarios. Por este motivo el óxido de etileno, utilizado actualmente en el ámbito hospitalario, no se encuentra aún en el registro de biocidas, ya que estos productos se siguen registrando en la Agencia de Medicamentos y Productos Sanitarios durante el periodo transitorio establecido en la Directiva.

Por otro lado, el dióxido de cloro (notificado como producto de tipo 4), aunque es una de las cinco sustancias activas con mayor volumen de producción en Europa, no cuenta con ningún IAT inscrito en el registro español para la elaboración de formulados de uso en la industria alimentaria.

Por último señalar que en España, los formulados elaborados con sustancias activas pertenecientes al grupo de compuestos de amonio cuaternario son los que cuentan con un mayor número de registros para uso ambiental y en industria alimentaria, esto contrasta con el hecho de que ninguna de estas sustancias activas se encuentre entre las de mayor volumen de producción en Europa.

Una de las conclusiones que resulta de este trabajo es que más de la mitad de las sustancias activas desinfectantes (tipos 2 y 4) que se están evaluando a nivel europeo para ser incluidas en los anexos, forman parte de IAT y formulados registrados en España. No obstante, algunas de las discordancias señaladas anteriormente con respecto a las sustancias más importantes notificadas en Europa sugieren que podrían existir diferencias relacionadas con los patrones de uso.
En un futuro sería interesante conocer el patrón de uso en España de estos desinfectantes y compararlos con los de otros países europeos.

Por otro lado, el principio de reconocimiento mutuo, por el que los biocidas autorizados en un estado miembro serán autorizados, previa solicitud, en otro estado miembro, así como la posible creación de un registro comunitario de biocidas, recogido en la propuesta del futuro reglamento de biocidas $^{20}$, probablemente tenga como resultado una uniformidad en el uso de biocidas en el mercado europeo y así como en la cantidad y tipo de desinfectantes autorizados.

Finalmente señalar que, es de esperar que la progresiva introducción en los anexos de las sustancias activas desinfectantes prevista para los próximos 4 años, produzca nuevos cambios en el registro de biocidas. La revisión de las sustancias activas, que incluye una valoración de riesgo de las mismas en las condiciones y escenarios de uso, posiblemente introducirá más restricciones en los requisitos actuales de autorización, relacionados con el manejo, utilización, almacenamiento, transporte y eliminación de las sustancias y mezclas.

\section{BIBLIOGRAFÍA}

1. Diario Oficial de las Comunidades Europeas. Directiva 98/8/CE del Parlamento Europeo y del Consejo de 16 de febrero de 1998, relativa a la comercialización de Biocidas. DOCE núm. L 123 de 24/4/1998.

2. Diario Oficial de las Comunidades Europeas. Reglamento (CE) 1896/2000 de la Comisión, de 7 de septiembre de 2000 , relativo a la primera fase del programa contemplado en el apartado 2 del artículo 16 de la Directiva 98/8/CE del Parlamento Europeo y del Consejo sobre Biocidas. DOCE núm. L 228 de 8/9/2000.

3. Diario Oficial de la Unión Europea. Reglamento (CE) 1451/2007 de la Comisión, de 4 de diciembre de 2007, relativo a la segunda fase del programa de trabajo de diez años contemplado en el artículo 16, apartado 2, de la Directiva 98/8/CE del Parlamento Europeo y del Consejo relativa a la comercialización de biocidas. DOCE núm. L 325 de 11/11/2007. 
4. Diario Oficial de la Unión Europea. Directiva 2009/107/CE del Parlamento Europeo y del Consejo de 16 de septiembre de 2009, por la que se modifica la Directiva 98/8/CE, relativa a la comercialización de biocidas, en cuanto a la ampliación de determinados plazos. DOCE núm. L 262 de 6/10/2009

5. Boletín Oficial del Estado. Real Decreto 3349/1983, de 30 de noviembre, por el que se aprueba la Reglamentación Técnico-Sanitaria para la fabricación, comercialización y utilización de plaguicidas. BOE núm. 20 de 24/1/1984.

6. Boletín Oficial del Estado. Real Decreto 162/1991, de 8 de febrero, por el que se modifica la Reglamentación Técnico-Sanitaria para la fabricación, comercialización y utilización de los plaguicidas. BOE num. 40 de $15 / 2 / 1991$

7. Boletín Oficial del Estado. Real Decreto 443/1994, de 11 de marzo, por el que se modifica la Reglamentación Técnico-Sanitaria para la fabricación, comercialización y utilización de los plaguicidas. BOE num. 76 de 30/3/1994.

8. Boletín Oficial del Estado. Real Decreto 1054/2002 de 11 de octubre por el que se regula el proceso de evaluación para el registro, autorización y comercialización de biocidas. BOE núm. 247 de 15/10/2002.

9. Josefa Moreno Marí, Amparo Meliá Llácer, María Teresa Oltra Moscardó y Ricardo Jiménez Peydró. Situación actual en España de los aerosoles insecticidas registrados en sanidad ambiental para uso doméstico. Rev Esp Salud Pública. 2003; 77:383-391

10. Josefa Moreno Marí, Jesús López Ferrer y Ricardo Jiménez Peydró. El control de los roedores: Revisión de los rodenticidas registrados en el ámbito de la sanidad ambiental en España. Rev Esp Salud Pública. 2004; $78: 5-16$

11. Campos Rodríguez S, Reinares Ortiz de Villajos J, García Martín S, González Márquez ML y Álvaro Gómez BA. Impacto de la Directiva 98/8/CE en los biocidas registrados en España para tratamiento de torres de refrigeración (2006-2009). Rev Esp Salud Pública. 2009: 9(1): 91

12. Panorama actual de los biocidas (editorial). Panorama Actual Med 2009; 33(326):772-781

13. Ministerio de Sanidad, Política Social e Igualdad. Registro de Plaguicidas no agrícolas o Biocidas (1 de mayo de 2010).

Disponible en: http://www.msps.es/ciudadanos/saludAmbLaboral/prodQuimicos

14. Comisión de las Comunidades Europeas. Biocides: Substances included in Annex I or IA to Directive
98/8/EC. Actualizado a fecha 19/04/2010 y disponible en:

http://ec.europa.eu/environment/biocides/annexi_and ia.htm

15. Comisión de las Comunidades Europeas. Existing active substances for which a decision of non-inclusion into Annex I or IA of Directive 98/8/EC has been adopted. Actualizado a fecha 6/05/2010 y disponible en: http://ec.europa.eu/environment/biocides/pdf/list_date s_product_phasing_out.pdf

16. Comisión de las Comunidades Europeas. List of participants/applicants having submitted a dossier in accordance with Article 5(3) of Regulation (EC) No. 2032/2003 (by product-types). Actualizado a fecha 17/05/2010 y disponible en:

http://ec.europa.eu/environment/biocides/pdf/list_participants_applicants_prod.pdf

17. Comisión de las Comunidades Europeas. Report from the Commission to the council and the European Parliament. Evaluation of the implementation of Directive 98/8/EC concerning the placing of biocidal products on the market. Bruselas, $\operatorname{COM}(2008) 620$ final, $8 / 10 / 2008$.

18. Comisión de las Comunidades Europeas. Study on Impact of the implementation of Directive 98/8/EC concerning the placing on the market of biocidal products. Final Report for DG Environment European Commission, 10/10/2007.

19. Comisión de las Comunidades Europeas. Dirección general de medio ambiente. Assessment of different options to address risk from the use phase of biocides. Final report, Marzo de 2009. Disponible en: http://ec.europa.eu/environment/biocides/pdf/report_u se.pdf

20. Comisión de las Comunidades Europeas. Propuesta de Reglamento del Parlamento Europeo y del Consejo relativo a la comercialización y utilización de biocidas. Bruselas, COM (2009)267 final de 12/6/2009. 